Malaysian Journal of Social Sciences and Humanities (MJSSH)

Volume 4, Issue 7, November 2019

e-ISSN : 2504-8562

Journal home page:

www.msocialsciences.com

\title{
Analisis Makna Hidangan Pulut Kuning dalam Adat Bebantang Masyarakat Tidung, Pulau Sebatik, Sabah
}

\author{
Nor Adila Samuri ${ }^{1}$, Norhuda Salleh ${ }^{1}$ \\ 1Fakulti Kemanusiaan , Seni dan Warisan Universiti Malaysia Sabah (UMS) \\ Correspondence: Norhuda Salleh (norhudasalleh@ums.edu.my)
}

\begin{abstract}
Abstrak
Adat bebantang merupakan salah satu pelaksanaan tingkat adat dalam perkahwinan etnik Tidung di Pulau Sebatik, Sabah. Adat ini secara amnya merujuk kepada pasangan yang disandingkan di atas tilam (pelamin) sambil rombongan tetamu akan makan beramai-ramai berdekatan dengan pasangan pengantin. Pada masa yang sama, pulut kuning akan dihidangkan kepada pasangan pengantin yang diraikan. Hal ini berlaku demikian kerana pulut kuning merupakan hidangan wajib dalam adat bebantang yang mana menitikberatkan lima aspek utama iaitu aspek warna, jenis acuan, jenis bahan dan hiasan serta bekas yang digunakan dalam proses penyediaan makanan tersebut. Objektif kajian ialah menganalisis makna pulut kuning dalam pelaksanaan adat bebantang dari sudut pandang komunikasi bukan lisan. Kajian menggunakan pendekatan etnografi dengan pengkaji turut serta dalam adat yang dilaksanakan. Data diperoleh melalui temu bual mendalam bersama informan utama, mak andam dan pengamal adat. Lokasi kajian terletak di Kampung Mentadak Baru, Pulau Sebatik, Tawau, Sabah. Analisis data menjelaskan bahawa pulut kuning yang diterjemahkan menerusi bentuk, warna dan cara hidangan semasa pelaksanaan adat bebantang membawa makna kasih sayang, tanda keislaman, kebahagiaan dan kesuburan.
\end{abstract}

Kata kunci: adat bebantang, pulut kuning, Tidung, Pulau Sebatik

\section{Analysis of the Meaning in Serving The Yellow Glutinous Rice in the Custom of the Tidung Community, Sebatik Island, Sabah}

\begin{abstract}
The Adat Bebantang is the implementation of a stage of customs in the marriage of the Tidung ethnicity in Sebatik Island, Sabah. This custom generally refers to the newly married couple who are seated on a mattress (marital dais) while the bridal party will feast together near the newlyweds. At the same time, yellow glutinous rice will be served to the newlyweds. This is because yellow glutinous rice is a compulsory serving in the Adat Bebantang custom which emphasizes on the five main aspects namely color, type of mold, materials and decorations as well as the containers used in the food preparation process. The objective of the study is to analyze the meaning of the yellow glutinous rice in the implementation of the Adat Bebantang from the non-verbal communication perspective. The study uses an ethnographic approach with the researcher participating in the custom performed. Data is obtained through in-depth interviews with key informants, beautician and customs practitioners. The study area is located in Kampung Mentadak Baru, Sebatik Island, Tawau, Sabah. Data analysis explains that the yellow glutinous rice is translated through the shape, color and manner of serving the
\end{abstract}


dishes during the execution of the custom bringing about the meaning of love, Islamic symbolism, happiness, and fertility.

Keywords: adat Bebantang, yellow glutinous rice, Tidung, Sebatik Island

\section{Pengenalan}

Makanan dalam kehidupan manusia merupakan sumber keperluan tenaga bagi meneruskan kehidupan seharian. Beberapa penelitian mengenai makanan, pola pengambilan makanan hingga simbol yang terdapat pada makanan dalam ruang lingkup kajian antropologi telah dilakukan oleh Claude LeviStrauss: 1965, Sutton: 2001, Counihan: 2004). Oleh sebab itu, makanan bukan sahaja dirujuk sebagai keperluan seharian manusia malah jauh daripada itu. Hal ini kerana terdapat makna yang terkandung di sebalik makanan yang dihidangkan yakni disampaikan menerusi bentuk komunikasi bukan lisan seperti tunjuk ajar. Komunikasi bukan lisan ini menurut (Knapp 1972) adalah merujuk kepada hampir kesemua bentuk komunikasi yang berlaku dalam kehidupan manusia kecuali pertuturan atau ayat yang ditulis. Terdapat variasi dalam bentuk komunikasi bukan lisan namun bagi penemuan ini elemen artifak yang merupakan sebahagian daripada bentuk komunikasi bukan lisan menjadi paksi kepada penelitian yang dijalankan, "physical appearance clues also include what are called artifactual clues, such as jewelry, clothes, glasses and so forth"(Matsumoto, G. Frank \& Hyi Sung Hwang, 2011).

Kebiasaannya, masyarakat dahulu banyak mengungkapkan tunjuk ajar melalui simbol-simbol yang wujud sama ada melalui gerak badan, ekspresi muka mahupun objek(simbol) yang digunakan untuk menyampaikan maksud. Oleh hal yang demikian, kewujudan simbol ini amnya diangkat sebagai pengukur yang membawa makna yang mana diadun mengikut budaya masyarakat pelaksana. Norhuda Salleh (2017) menjelaskan simbol amnya berguna dalam mentafsirkan idea dan pemikiran yang wujud di sebalik proses adat dan objek fizikal sesebuah kebudayaan. Sebagai contohnya, dalam masyarakat Melayu simbol makanan merupakan pelengkap bagi sesuatu perayaan seperti Hari Raya, sesuatu majlis seperti perkahwinan, kenduri arwah, majlis cukur jambul (bagi bayi yang baru lahir) dan aktiviti ritual tradisi yang lain. Pernyataan ini adalah seiring dengan masyarakat Tidung yang turut menggunakan makanan sebagai elemen(simbol) yang mempunyai makna bagi sesebuah upacara atau adat. Sebagai contohnya gulai putih dijadikan hidangan yang sinonim dalam kenduri arwah masyarakat Tidung yang membawa makna kepada cerita rakyatnya.

\section{Adat Bebantang}

Masyarakat Tidung adalah kaya dengan budaya ketara dan tidak ketara. Populasi etnik ini di Sabah adalah seramai 27,675 orang yang mana terdiri daripada 13,935 orang lelaki serta 13,740 orang perempuan (Banci Penduduk \& Perumahan Malaysia, 2010) kebanyakan etnik Tidung tertumpu di bahagian Tawau, Sandakan dan Beluran. Abdul Munir Hafizy (2005), menyatakan bahawa etnik Tidung mempunyai pengamalan adat yang dekat dengan masyarakat Melayu tetapi turut mempunyai perbezaan. Oleh hal yang demikian adat perkahwinan merupakan antara upacara yang boleh diteliti untuk melihat persamaan serta perbezaan yang wujud. Ini kerana dalam pelaksanaan adat perkahwinan terkandung pelbagai simbol yang secara tidak langsung membawa makna yang pelbagai.

Dalam adat perkahwinan masyarakat Tidung terdapat sebelas peringkat pelaksanaan adat perkahwinan yang setiap satu-satunya membawa tujuan tersendiri. Sebagai contohnya, adat bebantang yang merupakan salah satu tingkat adat yang dilaksanakan oleh masyarakat Tidung dalam adat perkahwinan mereka. Sesetengah masyarakat Tidung menamakan adat ini sebagai bedulug yang juga membawa kepada makna yang sama. Dalam bahasa Melayu bebantang atau bedulug ini adalah merujuk sebagai adat bersanding. Dalam adat ini pasangan akan disandingkan dengan duduk di atas tilam (pelamin) sambil rombongan tetamu akan makan beramai-ramai berdekatan dengan pengantin. 
Ketika adat ini dilaksanakan terdapat makanan wajib yang perlu dihidangkan iaitu pulut kuning. Begitu juga dengan masyarakat Melayu, pulut kuning atau beras pulut kuning yang dikukus adalah penting dalam pengamalan budaya, ritual, tradisi dan adat (Wijaya, 2011). Bagi masyarakat Melayu pulut kuning ialah hidangan istimewa yang kebiasaannya untuk sesebuah majlis yang mempunyai makna rasa hormat dan bersyukur serta kekuatan atau keakraban sesebuah hubungan kekeluargaan.

Idea yang dibawa oleh Wijaya adalah seiring dengan pendapat Norhuda Salleh (2017), iaitu peranan pulut kuning yang menandakan simbol ikatan kekeluargaan yang kuat dengan mempertimbangkan sifat pulut kuning yang melekat(melekit). Sementara itu, dalam pelaksanaan adat bebantang ini pengantin juga perlu minum air putih bagi kedua-dua pasangan. Tujuan air ini dihidangkan dan perlu diminum adalah diharapkan kehidupan pasangan ini akan sejuk seperti mana sejuknya air putih yang diminum tersebut. Perkara ini secara tidak langsung membuktikan bahawa masyarakat Tidung turut mengaplikasikan makna sesuatu hidangan yang dihidangkan namun di dalam kertas kerja ini dapatan yang difokuskan hanya kepada hidangan pulut kuning sahaja.

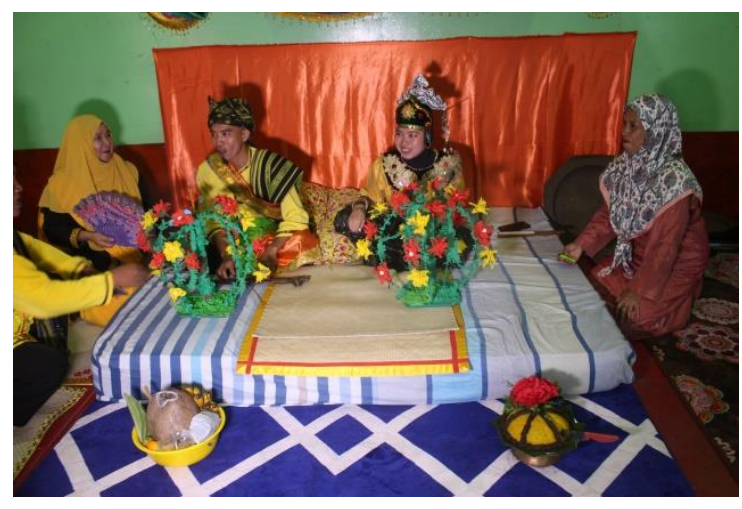

Gambar 1:Adat bebantang masyarakat Tidung di Kg Mentadak Baru, Pulau Sebatik. Sumber: Kajian lapangan Julai 2019

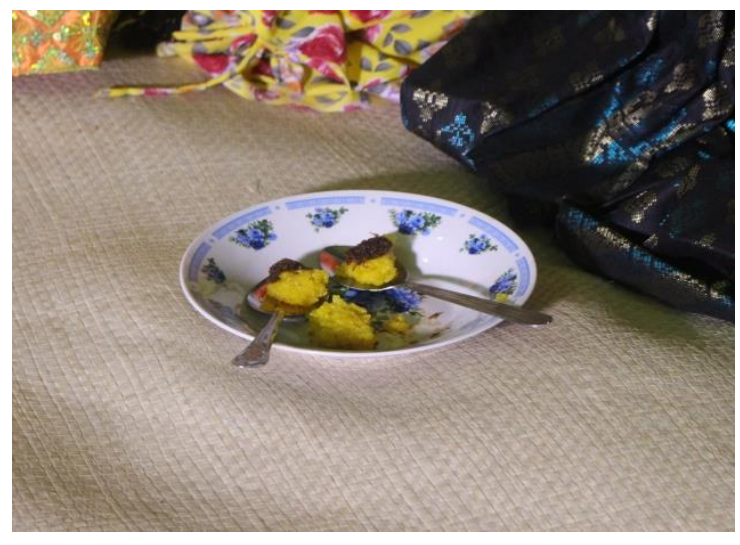

Gambar 2: Potongan pulut kuning yang dihidangkan dalam adat perkahwinan masyarakat Tidung. Sumber: Kajian lapangan Julai 2019 


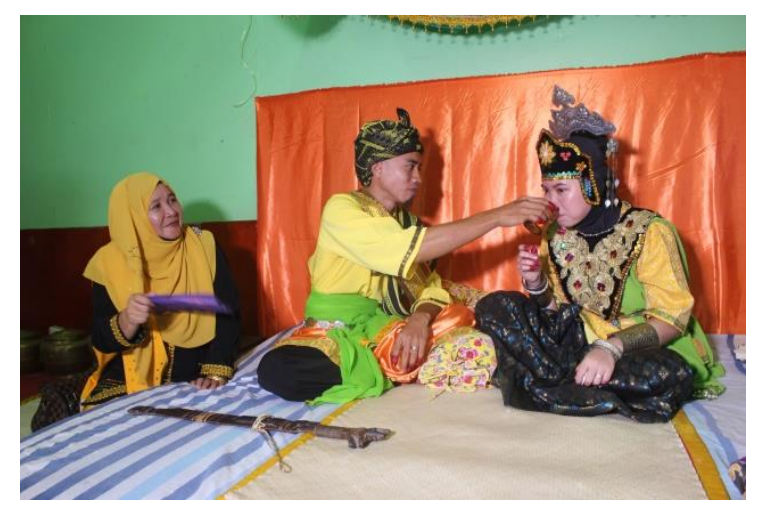

Gambar 3: Adat bebantang - pengantin lelaki memberi minum air kepada pengantin perempuan. Sumber: Kajian lapangan Julai 2019

\section{Sorotan Literatur}

Makanan adalah merujuk kepada simbol yang kaya dengan pelbagai makna bagi melambangkan sesebuah etnik atau masyarakat. Pernyataan ini adalah seiring dengan pendapat Shuirdy, Nurul Aisyah, Nik Mohd, Hamizad \& Mohd Salehuddin (2013, hal 29) yang mana makanan adalah kaya dengan simbolisme kerana ia adalah berkepentingan dalam kehidupan manusia di samping berperanan dalam adat dan tradisi serta budaya bagi sesebuah masyarakat. Whitt (2011), pula menyatakan bahawa makanan adalah penting bagi mengenal pasti identiti budaya bagi sesebuah etnik. Hal ini kerana makanan tidak hanya melambangkan identiti peribadi seseorang dalam kehidupan tetapi juga merupakan cermin bagi sesebuah identiti masyarakat, perbezaan antara budaya dan mencipta sempadan. Jauh dari itu, simbol makanan ini turut wujud dalam sesuatu adat bagi membawa makna tertentu sebagaimana yang dinyatakan oleh Foster \& Anderson (1978, hal:317) makanan sebagai simbol menyatakan hubungan antara individu-individu dan kelompok-kelompok, juga di dalam kelompok.

Kajian berhubung makanan telah direkodkan seawal tahun 1848 oleh ahli sosiologi Karl Marx sebagaimana yang telah direkodkan Engels (1969). Hasil daripada itu, Marx mendapati terdapat perbezaan terhadap kualiti makanan yang diambil oleh pekerja pada masa itu kerana makanan dihidangkan mengikut kelas-kelas tertentu yang secara tidak langsung membawa makna status sosial terhadap mereka. Kemudiannya, muncul pula ahli sosiologi dan antropologi lain yang menyusul seperti Durkheim \& Mauss (1963) yang membuat kajian berhubung makanan, masa makan dan cara memasak sesuatu makanan mengikut budaya masyarakat yang menyediakan makanan tersebut.

Sehubungan itu, terdapat juga sarjana lain menyifatkan makanan sebagai jambatan ke dunia ekspresi, budaya dan penghasilan dalam masyarakat(Welch \& Scarry, 1995; Gutierrez, 1999; Freeman, 2002; Cusak, 2003; Gold, 2007; Williams-Forson, 2007; Quah, 2008).

Aishah@ Eshah(1999) menerusi artikel jurnal gender, makanan dan identiti Melayu memperlihatkan hidangan nasi dingin ini hanya boleh dihidangkan serta dimakan oleh golongan wanita sahaja. Ini kerana hidangan ini perlu melalui transisi perubahan kepada nasi goreng terlebih dahulu jika ingin dihidangkan kepada golongan lelaki. Menerusi situasi ini, Aishah ingin menunjukkan bahawa wujud perbezaan status terhadap golongan wanita dan lelaki menerusi makanan yang dihidangkan. Bukan itu sahaja, tempat makan atau kedai kopi kebiasaannya didominasi oleh kaum lelaki. Perkara ini sedemikian kerana ia dianggap suatu situasi yang normal bagi kaum lelaki namun bagi kaum wanita ia memaparkan serta memaknakan satu konotasi negatif. Walaupun begitu, jika perkara tersebut merupakan komitmen bagi wanita tersebut maka ini tidak menjadi isu yang mempunyai makna yang tersirat terhadapnya.

Selanjutnya Sorre (1962) melihat bagaimana makanan berfungsi sebagai satu simbol penciptaan yang mempunyai makna dalam agama Kristian. Di samping itu, beliau juga turut membincangkan makanan 
dan hubungannya dengan ketidakseimbangan sosial yang berlaku. Menurutnya, diet adalah perlu namun bukan hanya membuat analisis terhadap sumber makanan tetapi bagaimana makanan tersebut disediakan turut perlu dikaji. Pandangan Sorre ini disokong oleh Grainers (1976, hal:8) yang menyentuh dari sudut geografi yang mana makanan bukan dilihat hanya sebagai makanan semata-mata tetapi perlu dilihat hubungannya dengan alam sekeliling. Ini amat bertepatan sebagaimana yang diketengahkan oleh Rozin (1982).

Rao (1986) pula menjelaskan tabiat dalam penyediaan makanan juga turut dipengaruhi oleh keadaan ekonomi dan alam sekitar. Sebagai contohnya berlaku adaptasi terhadap penyediaan makanan yang ingin dihidangkan. Kacang soya merupakan makanan yang digemari oleh masyarakat Cina. Atas faktor untuk menjimatkan tenaga bahan api, mereka telah menerima pengambilan bean sprouts (tauge dari kacang soya) sebagai salah satu sumber makanan yang masih dapat membekalkan khasiat makanan dari kacang soya. Untuk memasak tauge ini ia memerlukan masa yang singkat sahaja berbanding dengan biji kacang soya. Beliau menyatakan bahawa budaya itu sifatnya bukan statik. Hal ini demikian kerana di samping mengekalkan tradisi ia turut mampu untuk membangunkan mekanisme untuk berubah. Oleh itu, hal ini secara tidak langsung menjadi faktor perubahan kepada tabiat makan mengikut masa kerana berlakunya perubahan ekologi dan ekonomi. Antara faktor lain yang turut menjadi pemangkin kepada perubahan ini termasuklah sudut ketersediaan bahan, inovasi makanan dan difusi kesan daripada percampuran dengan berbagai-bagai bangsa lain.

Semiotik dalam linguistik dan budaya merupakan sebahagian daripada teori komunikasi. Pernyataan ini disebabkan oleh kedua- duanya mengkaji tentang tanda dan simbol (termasuk cara manusia bercakap, menulis, menyanyi, bau, gerak tubuh, imej, muzik, seni dan sebagainya) di mana manusia menyatakan perasaan, fikiran,buah fikiran dan ideologi menerusinya. Kajian ini mencakupi bagaimana makna diterjemahkan melalui tanda dan sistem simbol yang wujud yakni mampu untuk difahami semasa persepsi dan interpretasi keadaan yang berlaku. Analisis semiotik memfokuskan kepada budaya dan bentuk psikologi yang menjadi asas kepada bahasa, seni dan lain-lain ekspresi budaya yang digunakan sebagai alat untuk membantu mempersembahkan serta sekali gus memberi makna bagi sesuatu kejadian yang berlaku. Antara individu yang terkenal dalam bidang ini ialah Ferdinand de Saussure, 1857-1913 (bapa linguistik moden), Charles Sanders Peirce, 1839-1913 (pengasas doktrin pragmatisme) dan Roland Barthers, 1915-1980.

Merujuk kepada istilah semiotik, ia merupakan ilmu yang mencakupi pelbagai disiplin ilmu yang ada seperti kajian bahasa terutamanya, tanda (sign), simbol, seni bina dan reka bentuk visual (Sobur, 2009, hal:95-96). Hal ini demikian kerana banyak kajian terdahulu telah dijalankan berkenaan dengan semiotik baik semiotik terhadap bahasa, reka bentuk lambang atau logo mahupun semiotik terhadap iklan. Oleh itu, kerangka konsep dalam penelitian ini menggunakan semiotik Peirce (1839-1913). Pierce (Sobur, 2009) menjelaskan Sistem Tanda Peirce (1839-1913) memberi fokus pada tiga aspek bagi objek iaitu ikon, indeks dan simbol. Di samping itu, ia juga terfokus kepada aspek representasi yang terdiri dari tiga perkara yang dilihat iaitu qualisign (sifat), sinsign (kebenaran) dan juga legisign(peraturan). Kajian akan dilakukan dengan mengikut kepada teori semiotik Peirce (1839-1913) iaitu triadik dan melalui penghuraian elemen tanda qualisign terhadap simbol makanan yang dihidangkan dalam adat bebantang dalam perkahwinan masyarakat Tidung di Kampung Mentadak Baru, Pulau Sebatik.

Pendekatan kajian ini menjelaskan ikon berfungsi sebagai penanda yang serupa dengan bentuk yang ingin dirujuk. Indeks pula merupakan sesuatu yang melaksanakan fungsi sebagai penanda yang mengisyaratkan petandanya yang mana dirujuk kebenarannya. Sedangkan simbol pula merupakan penanda yang melaksanakan fungsi sebagai penanda yang mana telah digunakan secara tradisional dan lazimnya digunakan dalam masyarakat (Freddy, 2000). Objek dalam kajian ini ialah makanan yang disajikan ketika adat bebantang(bersanding) yang mempunyai beberapa elemen, iaitu daripada sumber warna rasa dan cara hidangan makanan dihidangkan.

Peirce (1839-1913) menyebut tanda ini sebagai representasi(perwakilan) manakala objek pula dirujuk sebagai suatu konsep, benda atau gagasan. Manakala makna merupakan persepsi, pemikiran dan perasaan serta interpretasi yang diperoleh daripada sebuah tanda yang diberikan (Danesi, 2004). 
Tambahan itu juga, model tanda yang dikemukakan oleh Peirce (1839-1913) adalah turut juga dikenali sebagai trikotomi atau triadik.

Mengikut Peirce lagi (1839-1913) proses pemaknaan tanda ini mengikut hubungan di antara tiga titik iaitu perwakilan (R), objek (O), dan interpretasi (I). Hal ini demikian kerana (R) merupakan bahagian tanda yang dapat dipersepsi secara fizikal yang amnya merujuk kepada sesuatu yang diwakili olehnya $(\mathrm{O})$, kemudian (I) pula ialah sebahagian daripada proses yang mentafsirkan hubungan (R) dan (O).

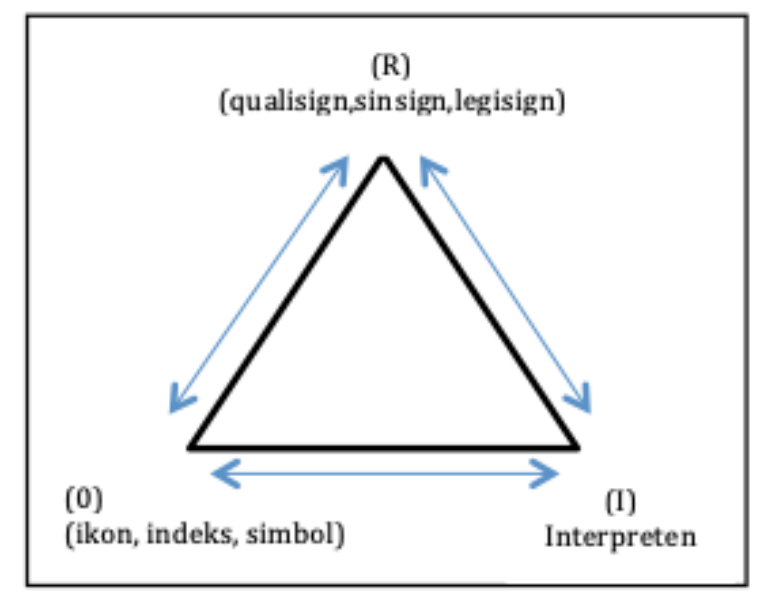

Rajah 1: Sistem Tanda Peirce 1839-1914

(Sumber: Sobur, 2009)

Landasan teori yang digunakan dalam kajian ini Teori semiotik Peirce (1839-1913) yang dilihat berkaitan secara langsung dalam fokus kajian yang ingin dijalankan. Oleh itu, penulisan ini akan memaparkan gambaran asas teori ini yang dihubungkaitkan dengan kajian komunikasi khasnya dalam bidang komunikasi bukan lisan. Justeru, pemikiran yang dipegang dalam kajian ini bagi melihat kepada aspek komunikasi bukan lisan adalah merujuk kepada pendekatan Matsumoto, G. Frank \& Hyi Sung Hwang(2011) yang menyatakan fungsi komunikasi bukan lisan ini terbahagi kepada tiga. Ia adalah menjelaskan(define), mengawal(regulate) dan pesanan (be the message). Kerelevanan kajian berkaitan bentuk komunikasi bukan lisan dapat dilihat kepada pernyataan Anjali Hans\& Emmanuel Hans(2015) yang menyatakan bahawa dalam kehidupan seharian, manusia hanya akan berkomunikasi dengan menggunakan perkataan hanya pada kadar 7 peratus sahaja dan selebihnya menerusi bentuk komunikasi bukan lisan(93\%). Maka, berlandaskan pegangan ini pemaknaan terhadap simbol (makanan) dapat dikaitkan dengan jelas berikutan penggunaan simbol ini salah satu bentuk komunikasi lisan yang mana ia boleh ditafsirkan maknanya menerusi landasan teori Charles Senders Pierce(1839-1913).

\section{Metodologi Kajian}

Perbincangan ini diasaskan kepada kajian yang dilakukan di satu kampung yang dalam kalangan pendudukannya terdapat individu yang masih menyimpan peralatan Tidung terdahulu serta masih kuat mengamalkannya.

Pengumpulan data menggunakan pendekatan etnografi dengan pengkaji turut serta dalam adat berbantang. Sesi temu bual secara mendalam bersama informan utama yang terdiri daripada mak andam dan pengamal adat serta ketua kampung dilakukan bagi memperoleh maklumat. Bagi membantu untuk mengumpulkan data, bantuan alat perakam digunakan dan proses mencatat maklumat turut dilaksanakan dari semasa ke semasa. 


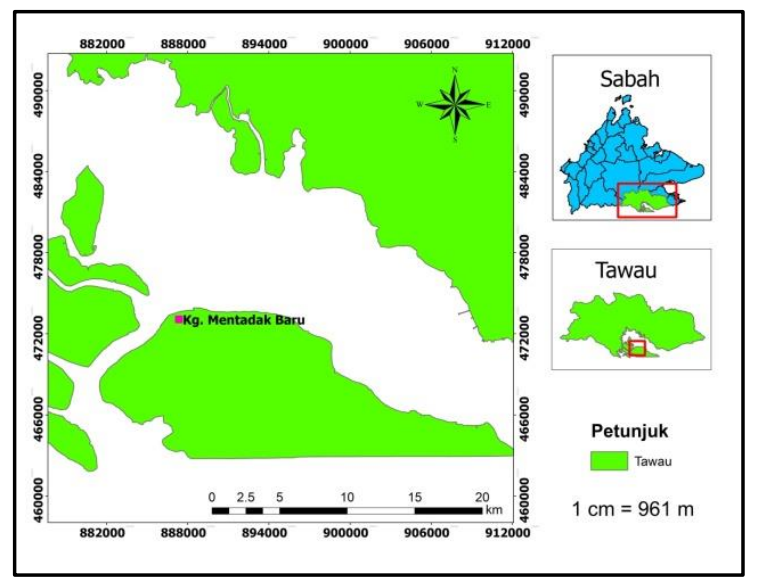

Peta 1: Lokasi kajian (Kampung Mentadak Baru, Pulau Sebatik, Sabah Malaysia

\section{Dapatan \& Perbincangan}

Hidangan pulut kuning atau turut disebut sebagai pulut pengantin merupakan hidangan wajib bagi adat bebantang dalam pelaksanaan perkahwinan masyarakat Tidung di Pulau Sebatik Tawau, Sabah. Hidangan ini adalah amat sinonim bagi meraikan pasangan pengantin berserta kaum keluarga yang mana amnya mengandungi makna secara tersirat di sebalik penyediaannya dan hidangannya.

\section{Bahan-Bahan Pulut Kuning}

Bahan yang diperlukan untuk menyediakan pulut kuning ini terdiri daripada lima bahan utama. Ia terdiri daripada beras pulut, kunyit hidup, garam, santan kelapa dan daun pandan. Penggunaan bahanbahan ini bukan hanya meliputi sifat bahan ini sebagai bahan masakan namun ia mengandungi makna yang unik mengikut kepercayaan dan pengamalan etnik Tidung.

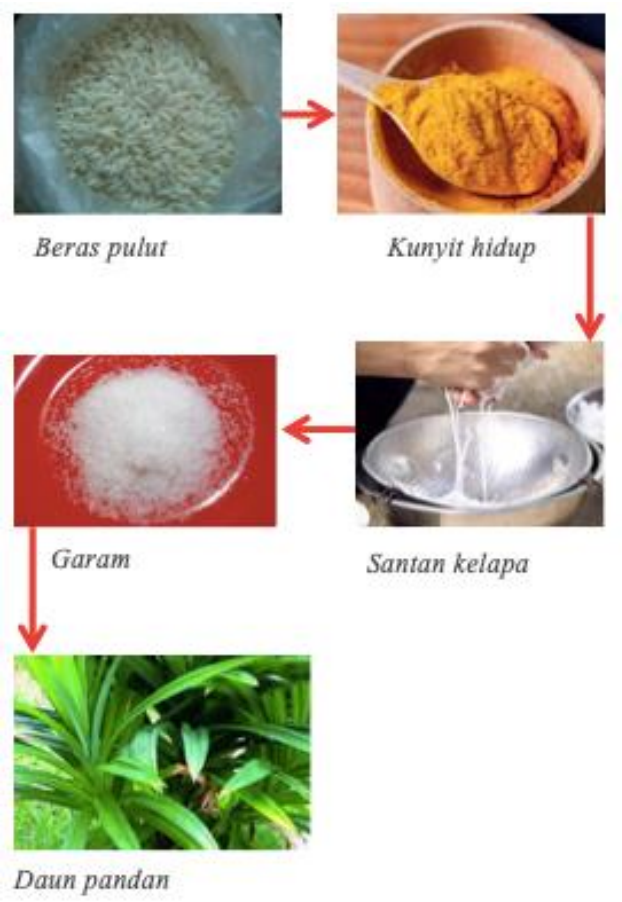


Namun hanya etnik Tidung Sembakung yang menyebut akan bahawa penggunaan kunyit dalam pulut kuning ini amnya membawa makna kepada sifat kunyit. Hal ini kerana sifat kunyit yang amnya semakin tua warna kuningnya akan semakin cantik. Oleh sebab itu, diharapkan cantiknya warna kuning itu diibaratkan cantiknya pengantin yang dilihat berseri-seri.

\section{Penyediaan Pulut Kuning}

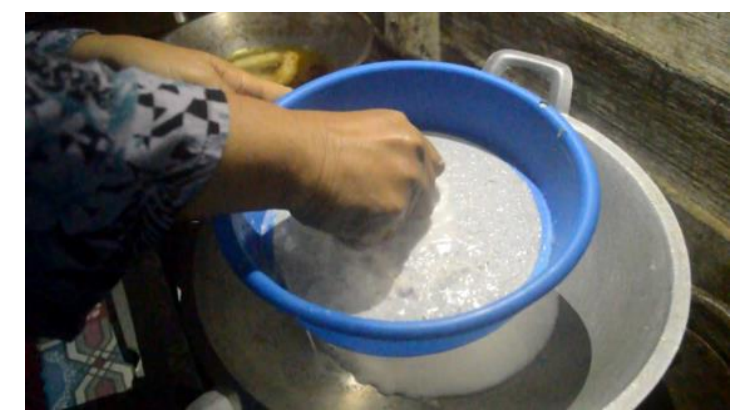

Gambar 4: Memasukkan santan ke dalam kuali yang dipanaskan secara perlahan. Sumber: kajian lapangan Julai 2019.

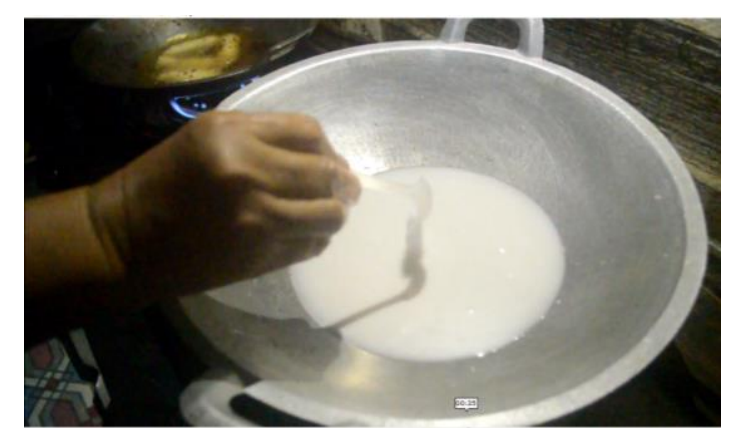

Gambar 4: Memasukkan garam ke dalam santan yang sedang dipanaskan secara perlahan. Sumber: kajian lapangan Julai 2019.

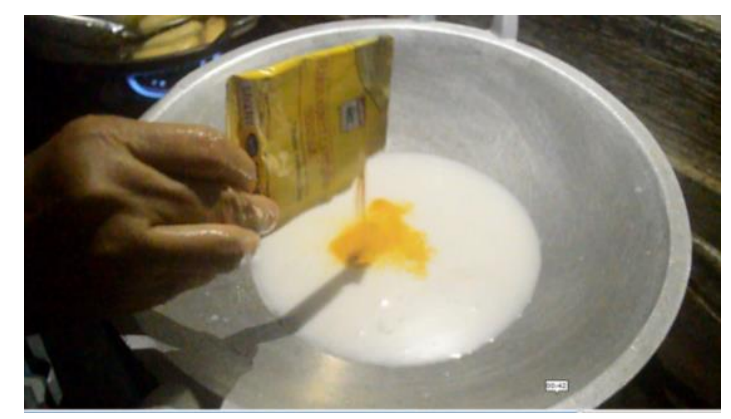

Gambar 5: Memasukkan kunyit ke dalam santan yang sedang dipanaskan secara perlahan. Sumber: kajian lapangan Julai 2019. 


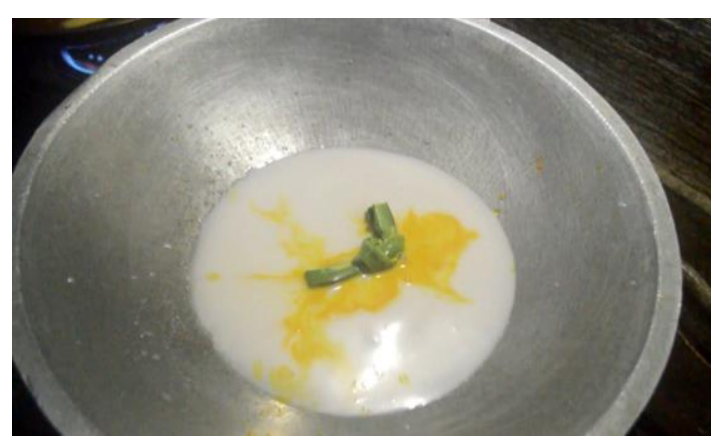

Gambar 6: Memasukkan daun pandan ke dalam santan yang sedang dipanaskan secara perlahan. Sumber: kajian lapangan Julai 2019.

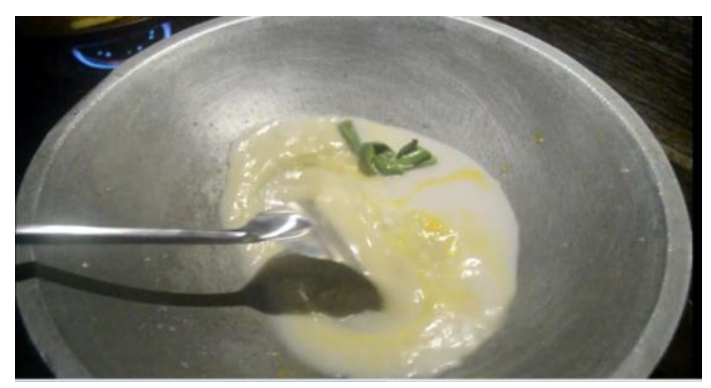

Gambar 7: Kacaukan bahan yang telah dimasukkan ke dalam kuali. Sumber: kajian lapangan Julai 2019.

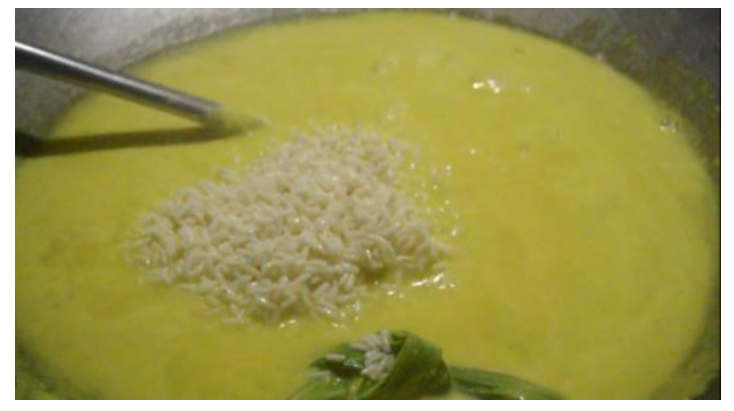

Gambar 8: Memasukkan beras ke dalam kuali.. Sumber: kajian lapangan Julai 2019.

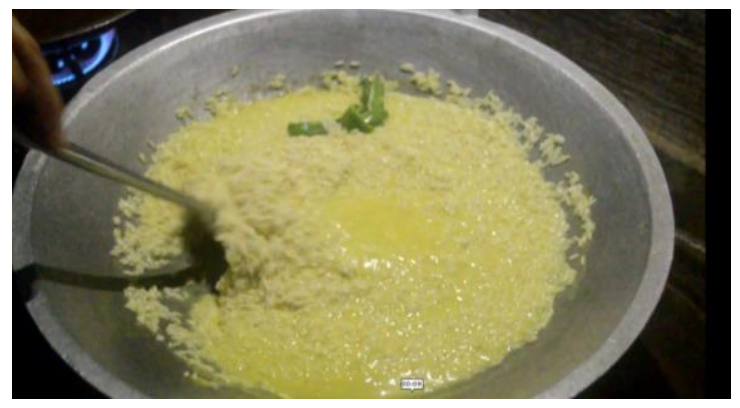

Gambar 9: Kacaukan bahan-bahan yang telah dimasukkan sehingga kering. Sumber: kajian lapangan Julai 2019. 


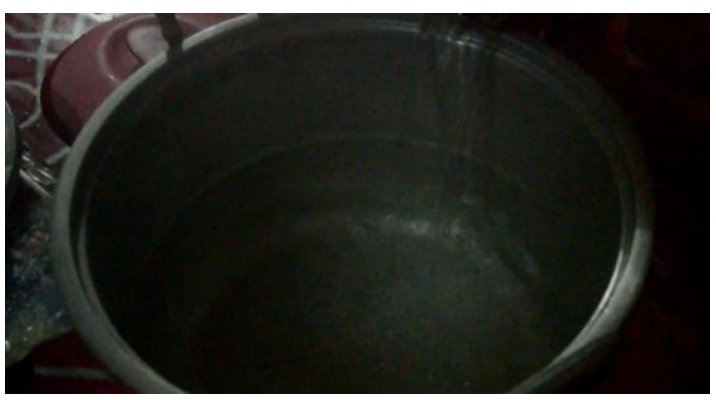

Gambar 10: Sediakan periuk dan masukkan air yang panas. Sumber: kajian lapangan Julai 2019

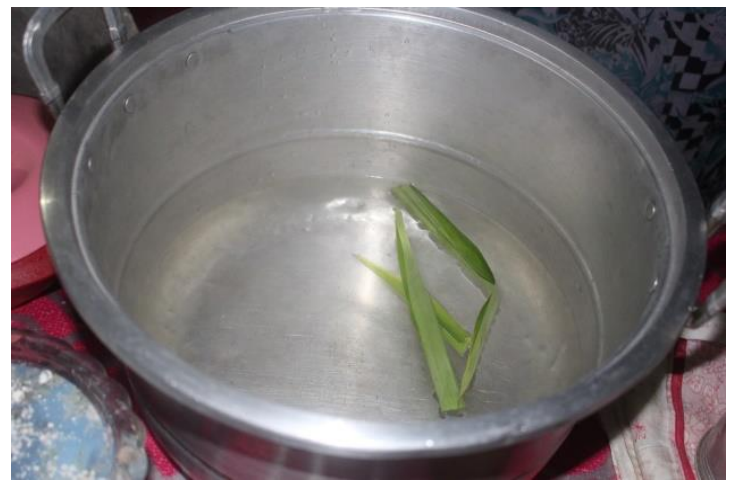

Gambar 11: Masukkan daun pandan ke dalam air. Sumber: kajian lapangan Julai 2019

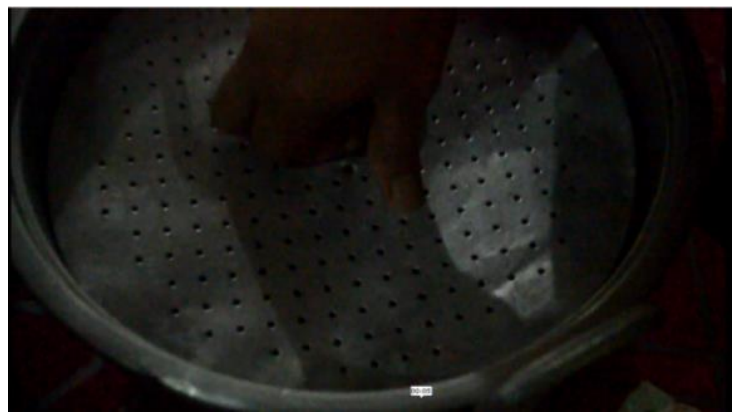

Gambar 12: Masukkan tapis pengukus. Sumber: kajian lapangan Julai 2019

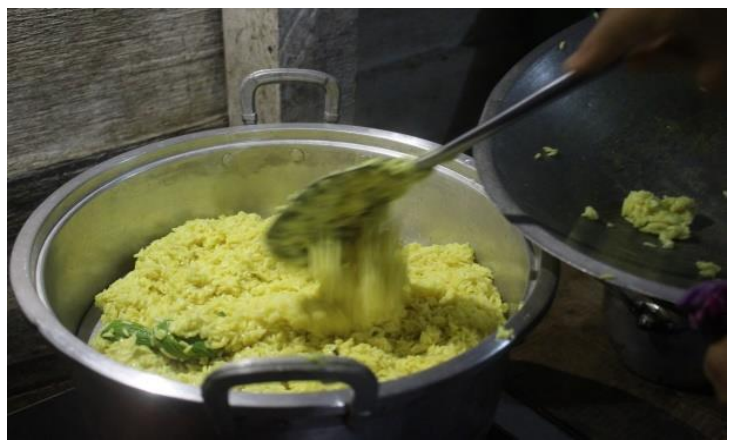




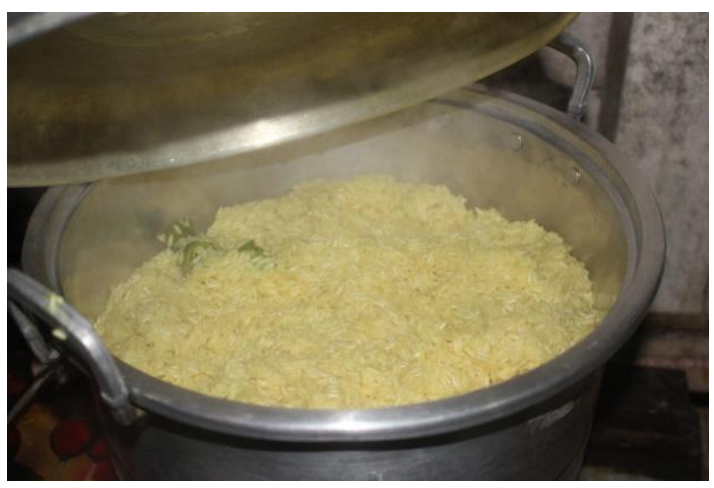

Gambar 13: Masukkan campuran beras pulut kuning yang telah dikeringkan ke dalam pengukus dan sedia untuk dikukus. Sumber: kajian lapangan Julai 2019

\section{Kelapa Manis@Antin-Antin}

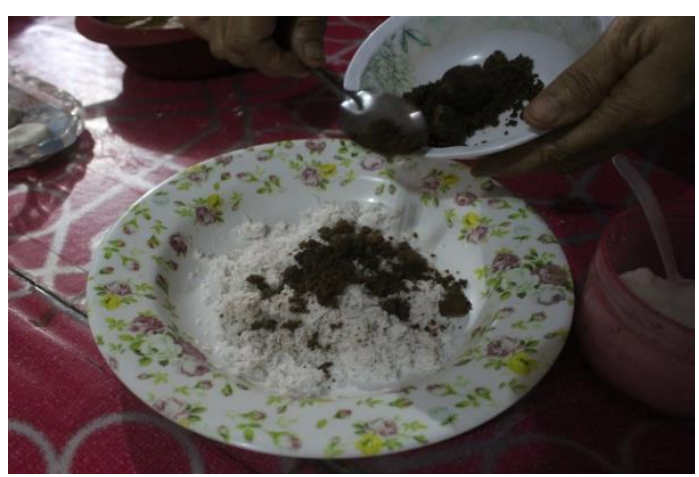

Gambar 14: Campurkan gula melaka ke dalam kelapa yang telah diparut. Sumber: kajian lapangan Julai 2019

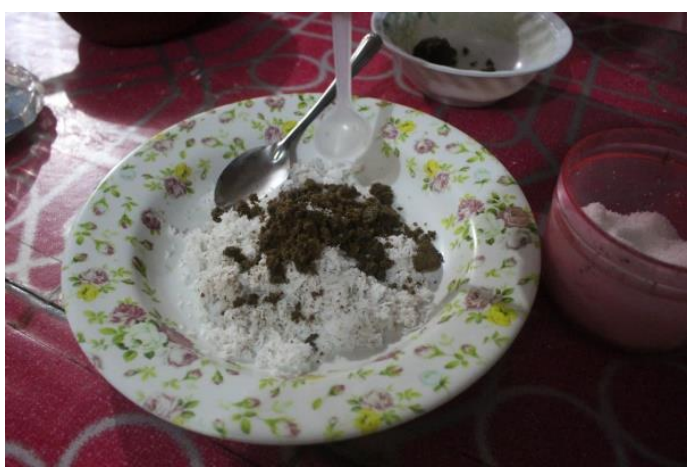

Gambar 15: Masukkan sedikit garam. Sumber: kajian lapangan Julai 2019 

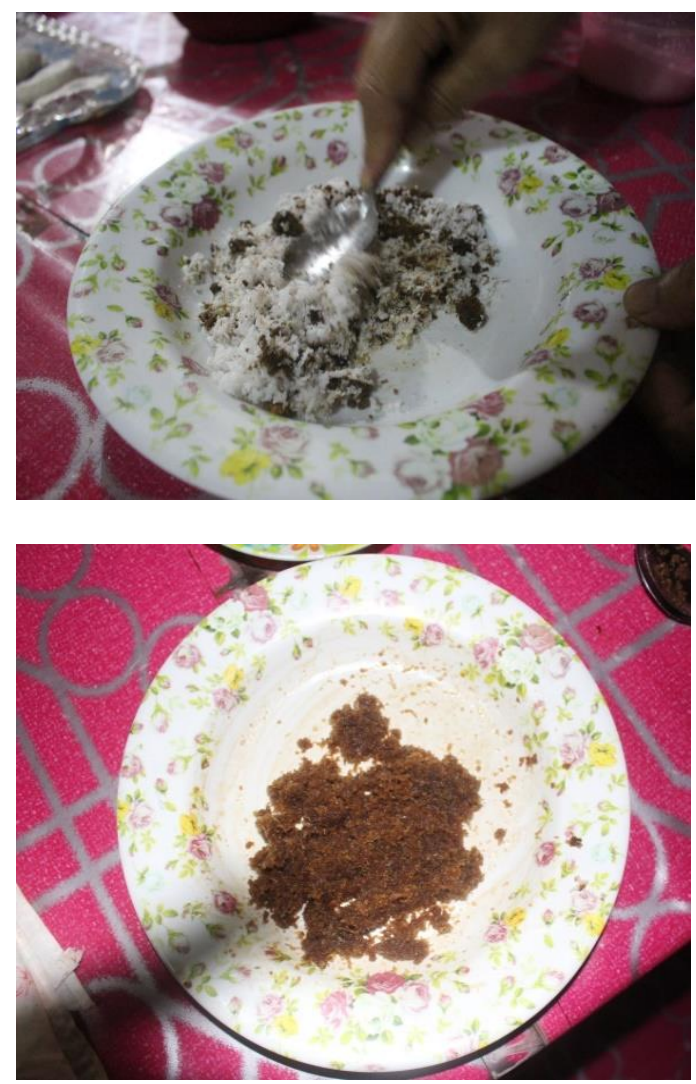

Gambar 16: Gaulkan bahan yang dicampurkan sehingga rata. Sumber: kajian lapangan Julai 2019

\section{Pulut Kuning}

Terdapat enam elemen(sifat) yang menjadi penentu kepada tanda yang dimaknakan dari sudut qualisign mengikut pengamalan masyarakat Tidung dalam hidangan pulut kuning bagi adat bebantang. Ia terdiri daripada sifatnya, warna, rasa, motif, dan hiasan.

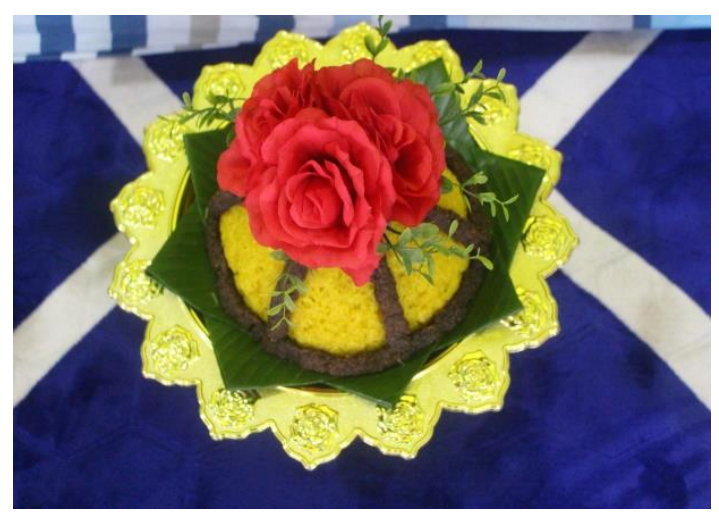

Gambar 16: Pulut kuning. Sumber: Kajian lapangan Julai 2019. 


\section{Sifat Pulut Kuning}

Melihat kepada sifat pulut kuning yang melekat(melekit), etnik Tidung percaya bahawa sifat ini sebenarnya membawa makna yang terbahagi kepada dua pecahan iaitu kepada pengantin sekali gus kepada kaum keluarga. Tujuan hidangan pulut kuning kepada pasangan pengantin amnya adalah diharapkan pasangan akan hidup sehidup semati. Namun bagi, ahli keluarga pula sifat ini tanggapi sebagai simbolik kepada ikatan kekeluargaan yang mana diharapkan ikatan ini akan kuat antara satu sama lain.

\section{Warna Pulut Kuning}

Pulut kuning sinonim dengan warna kuning. Menurut etnik Tidung khususnya Tidung Sumbol pemilihan warna kuning ini adalah disebabkan oleh beberapa punca utama. Ia adalah disebabkan oleh etnik Tidung Sumbol percaya bahawa warna kuning merupakan tanda keislaman pasangan tersebut. Namun bagi etnik Tidung Sembakung pula, warna kuning ialah warna kebanggaan mereka.

\section{Rasa Kelapa Manis(Antin-Antin)}

Kelapa manis atau disebut sebagai antin-antin dalam Bahasa Tidung bermaksud hiasan yang dibentuk di sekeliling pulut kuning.Hiasan ini dibentuk memanjang ke bawah dan terdiri daripada lima garisan dari atas ke bawah.

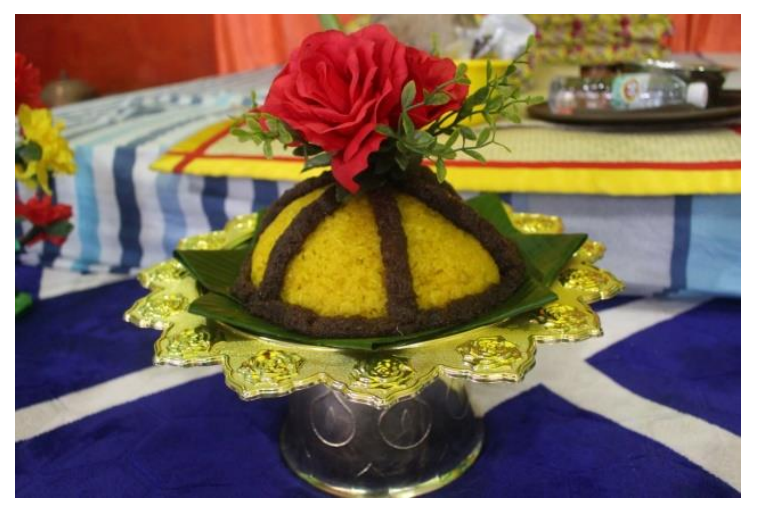

Gambar 17: Pulut kuning. Sumber: Kajian lapangan Julai 2019.

Simbolik penggunaan kelapa manis ini adalah bertujuan untuk membawa maksud diharapkan kehidupan pasangan yang berkahwin tersebut akan manis seperti mana manisnya kelapa manis tersebut. Dalam erti kata lain penggunaan kelapa manis ini juga membawa maksud diharapkan pasangan yang berkahwin ini akan bahagia dalam rumah tangga.

\section{Jalur Kelapa Manis(Antin-Antin)}

Jalur kelapa manis(antin-antin) ini terdiri daripada lima jalur. Menurut etnik Sembakung dan Nunukan jalur ini sebenarnya memberi pemaknaan yang mewakili rukun Islam yang terdiri daripada lima perkara. Hal ini demikian kerana memandangkan etnik Tidung majoritinya merupakan etnik yang beragam Islam maka pengaplikasian elemen-elemen Islam adalah dekat dengan pengamalannya.

\section{Hiasan}

Hidangan pulut kuning dalam adat perkahwinan masyarakat Tidung, turut memberi penekanan terhadap elemen hiasan. Hal ini demikian kerana perbezaan hiasan yang digunakan secara tidak langsung melambang jenis Tidung yang diwakili.

\section{(a) Bunga ros}


Bunga ros kebiasaannya ditanggapi sebagai sesuatu tumbuhan yang cantik untuk dipandang. Oleh hal yang demikian penggunaan bunga ros sebagai hiasan terhadap pulut kuning bagi etnik Tidung Tarakan amnya membawa makna perlambangan cantiknya pengantin yang diraikan dalam majlis yang dijalankan.

\section{(b) Telur ayam rebus}

Ayam ialah haiwan yang bertelur dengan banyak. Oleh hal yang demikian etnik Tidung menggunakan telur ayam sebagai simbol yang mana diharapkan pasangan pengantin yang diraikan ini subur seperti mana ayam yang bertelur banyak. Tambahan itu, telur yang digunakan sebagai hiasan dalam penyediaan pulut kuning adalah hanya satu biji sahaja. Menurut etnik Tidung Sumbol pemaknaan ini adalah bertujuan agar pengantin akan hidup bersama-sama dalam satu bumbung seperti mana bilangan telur yang hanya satu sahaja diletakkan di atas pulut kuning tersebut.

\section{Lapis Pulut Kuning (Daun Pisang)}

Penggunaan daun pisang yang diletakkan sebagai lapis untuk menghidangkan pulut kuning mempunyai simboliknya yang tersendiri. Melihat kepada sifat daun pisang yang mampu untuk membuatkan makanan akan menjadi lebih tahan lama untuk disimpan faktor yang menyebabkan pemilihan ini. Hal ini kerana daya tahan daun pisang ini diibaratkan kepada daya tahan pasangan yang berkahwin agar kuat menghadapi pancaroba kehidupan selepas di ijab kabulkan (hubungan yang tahan lama). Tambahan itu, lapis yang digunakan ini sebenarnya mempunyai bentuk yang menyerupai alas yang digunakan oleh bakal pengantin lelaki sewaktu ingin dinikahkan. Ia dikenali sebagai raja bersila. Simboliknya penggunaan alas ini adalah mengandungi makna kepada pasangan yang baru berkahwin tersebut iaitu raja dalam sehari atau kebiasaan disebut sebagai raja sehari.

\section{Kesimpulan}

Makanan pulut kuning dalam adat bebantang bagi etnik Tidung di Kampung Mentadak Baru, Pulau Sebatik Tawau Sabah ini membawa makna kasih sayang, tanda keislaman, kebahagiaan dan kesuburan yang dilihat dari sudut artifaknya iaitu sifat fizikal yakni terkait dengan salah elemen dalam bentuk komunikasi bukan lisan. Walaupun penelitian ini merujuk etnik yang sama iaitu Tidung namun perbezaan tetap wujud. Hal ini membuktikan bahawa latar belakang yang berlainan bagi jenis etnik Tidung yang wujud ini secara tidak langsung membawa persamaan dan perbezaan pemaknaan terhadap pulut kuning dalam pelaksanaan adat bebantang.

\section{Penghargaan}

Kajian ini merupakan sebahagian objektif dalam dana penyelidikan daripada Kementerian Pendidikan Malaysia (FRG0490-2018) yang bertajuk Warisan Budaya Sabah: Penerokaan Makna Simbol Dalam Ritual Komunikasi Adat Perkahwinan Masyarakat Tidung). Ketua Projek ialah Dr Norhuda Salleh.

\section{Rujukan}

Aishah@Eshah Hj. Mohamed, ., Sulong Mohamad, \& Haziyah Hussain, . (2010). Makanan Hantaran Dalam Perkahwian Melayu Kelantan: Adat dan Interpretasi. Jurnal E-Bangi, 5(1), 103-115. http://journalarticle.ukm.my/1613/1/esah010.pdf

Anjali Hans \& Emmanuel Hans(2015), Kinesics, Haaptics and Proxemics: Aspects of Non-Verbal Communication, https://pdfs.semanticscholar.org/22bc/8a4b4101c90361998abce62abcdc90fb114c.pf

Berger, A. A. (2002). Media and communication research methods: An introduction to qualitative and quantitative approaches. San Francisco: SAGE Publications. 
Cusak, I. (2003). Pots, pans and 'eating out the body': Cuisine and the gendering of African nation. Nation and nationalism, 9, 277-296.

Durkheim, E., \& Mauss, M. (1963). Primitive Classification. (R. Needham, Ed.). Chicago: University of Chicago Press.

David E. Sutton, (2001).Materializing Culture Remembrance of Repasts An Anthropology of Food and Memory, Berg Publishers

Engels, F. (1969). Condition of the Working Class in England. London; Granada: Otto Wigand, Leipzig.https://www.marxists.org/archive/marx/works/1845/condition-working-class/ch07.htm

Foster, G. M., \& Anderson, B. G. (1978). Medical Anthropology. New York: John Wiley \& Sons.

Freeman, E. (2002). The wedding complex: Forms of belonging in modern American culture. Durham: Duke University Press.

Gutierrez. (1999). Cajun foodways. Mississippi: University Press.

Gold, A. L. (2007). Changing foodways: Generational communication in a new American refugee population(Unpublished Doctoral Dissertation). North Dakota State University

Lévi-Strauss, C. (1965). The Culinary Triangle. Partisan Review 33, 586-95.

Levi-Strauss, C. (1975). The Raw and The Cooked Introduction to a science of mythology Translated from the French by John and Doreen Weightman. New York: Harper Colophon Books.

Matsumoto, D., G.Frank, M., \& Hyi Sung Hwang, (2011). Reading People: Introductin to the World of Nonverbal Behaviour. In D. Matsumoto, M. G.Frank, \& Hyi Sun Hwang (Eds.), Non Verbal Communication : Science and Application (pp. 3-14). Los Angeles: Sage Publication

Norhuda Salleh, (2017). Ritual Dan Simbol Dalam Adat Perkahwinan Masyarakat Melayu Sekinchan, Selangor

Quah, S. R. (2008). Home and kin: Family in Asia. Singapore: Time Academic Press.

Rao, M. S. A. (1986). Conservatism and change in food habits among the migrants in India: A study in gatrodynamics. In R. S. Khare \& M. S. A. Rao (Eds.), Food, Society, and Culture: Aspects in South Asian Food Systems (pp. 121-140). Durham, North Carolina: Carolina Academic Press.

Rozin, P. (1982). Human food selection: The interaction of biology, culture and individual experience. In L. M. Barker (Ed.), The psychobiology of human food selection (pp. 225-254). Bridgeport, Connecticut: AVI.

Shuhirdy, Nurul Aisyah, Nik, Hamizad, Mohd Salehuddin \& Mohd Zahari (2013). Pulut Kuning in Malay Society: The Beliefs and Practices Then and Now, 29-36

Sorre, M. (1962). The Geography of Diet. In P. L. Wagner \& M. W. Mikesell (Eds.), Readings in Cultural Geography (pp. 445-456). Chicago: University of Chicago Press.

Sobur, A. (2009). Semiotika Komunikasi (Edisi Keem). Bandung: PT. Remaja Rosdakarya.

Whitt, J. B. (2011). An appetite for metaphor: Food imagery and cultural identity In Indian fiction. Proquest Digital Dissertation, (UMI Number: 1493573).

Wijaya, A. H. W. (2011). The meanings of pulut kuning for Melayu Society in Hamparan Perak. Unpublished thesis, University Sumatera, Indonesia.

Williams-Forson, P. (2007). Chicken and chains: using African American foodways to understand Black indentities. In A. Bower (Ed.), African American Foodways: exploration of history and culture. United States: University of Illinois Press.

Welch, D. P., \& Scarry, C. M. (1995). Status related variation in foodways in the Moundville Chiefdom.American Antiquity, 60(3),397-419. http://dx.doi.org/10.2307/282257 